\title{
Mining Key Phrase Translations from Web Corpora
}

\author{
Fei Huang Ying Zhang Stephan Vogel \\ School of Computer Science \\ Carnegie Mellon University, Pittsburgh, PA 15213 \\ \{fhuang, joy, vogel\}@cs.cmu.edu
}

\begin{abstract}
Key phrases are usually among the most information-bearing linguistic structures. Translating them correctly will improve many natural language processing applications. We propose a new framework to mine key phrase translations from web corpora. We submit a source phrase to a search engine as a query, then expand queries by adding the translations of topic-relevant hint words from the returned snippets. We retrieve mixedlanguage web pages based on the expanded queries. Finally, we extract the key phrase translation from the secondround returned web page snippets with phonetic, semantic and frequencydistance features. We achieve $46 \%$ phrase translation accuracy when using top 10 returned snippets, and $80 \%$ accuracy with 165 snippets. Both results are significantly better than several existing methods.
\end{abstract}

\section{Introduction}

Key phrases such as named entities (person, location and organization names), book and movie titles, science, medical or military terms and others ${ }^{1}$, are usually among the most information-bearing linguistic structures. Translating them correctly will improve the performance of cross-lingual information retrieval, question answering and machine translation systems. However, these key phrases are often domain-specific, and people con-

${ }^{1}$ Some name and terminology is a single word, which could be regarded as a one-word phrase. stantly create new key phrases which are not covered by existing bilingual dictionaries or parallel corpora, therefore standard data-driven or knowledge-based machine translation systems cannot translate them correctly.

As an increasing amount of web information becomes available, exploiting such a huge information resource is becoming more attractive. (Resnik 1999) searched the web for parallel corpora while ( $\mathrm{Lu}$ et al. 2002) extracted translation pairs from anchor texts pointing to the same webpage. However, parallel webpages or anchor texts are quite limited, and these approaches greatly suffer from the lack of data.

However, there are many web pages containing useful bilingual information where key phrases and their translations both occur. See the example in Figure 1. This example demonstrates web page snippets ${ }^{2}$ containing both a Chinese key phrase “浮 士德” and its translation, “Faust”.

We thus can transform the translation problem into a data mining problem by retrieving these mixed-language web pages and extracting their translations. We propose a new framework to mine key phrase translations from web corpora. Given a source key phrase (here a Chinese phrase), we first retrieve web page snippets containing this phrase using the Google search engine. We then expand queries by adding the translations of topic-relevant hint words from the returned snippets. We submit the source key phrase and expanded queries again to Google to retrieve mixed-language web page snippets. Finally, we extract the key phrase translation from the second-round returned snippets with phonetic, semantic and frequency-distance features.

\footnotetext{
${ }^{2} \mathrm{~A}$ snippet is a sentence or paragraph containing the key phrase, returned with the web page URLs.
} 


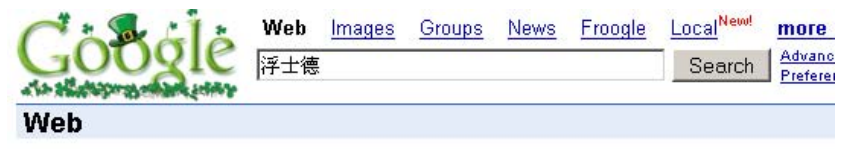

Tip: Try using pinyin for automatic Chinese keyword conversion. [Learn more about pinyin sea

浮士德 (一) - - 西文宝典-名著缩微-书海泛舟-动感校园-洪恩在线 - I Translate this …上帝坚信浮士德这样的人类的代表, 在追求中难免有的失误, 但在理性和智慧的引导 ...靡非斯特不同意上帝的看法, 他自信能将浮士德引向邪路, 让他阷落, 并为这事他 ... whw hongen . com/edu/shfz/mzsw/s1030403.htm - $9 \mathrm{k}$ - Cached - Similar pages

浮士德 (二) - 西文宝典-名著缩微-书海泛舟-动感校园-洪思在线 - [ Trans 1 : …玛甘泪的哥哥—一军人华仑亨, 一天晩上回家, 正好碰上浮士德再次前来与玛甘泪 .. 这时, 浮士德却逃出法网, 无忧无虑, 与靡非斯特一道赶赴下流淫荡的瓦普儿司的晚会 Www hongen com/edu/shzz/mzsw/s1030404. htm - 8k - Cached - Similar pages

莩士德的店[ 繁体]

whw between idv.tw/ - $1 \mathrm{k}$ - Cached - Similar pages

书目简介-世界文学-浮士德 - [ Translate this page ]

... 歌德的《浮士德》悲剧分上、下两部, 它㴖有始终一贯的故事情节, 而是以主人公 ... 五事业悲剧, 浮士德终身探索, 最后发现与人民进行创造性的劳动, 改造自然, 创造 ... 166.111.4.131/ $\mathrm{wmfg} / \mathrm{ydsm} 2 / \mathrm{smij} / 0066$. htm - $5 \mathrm{k}$ - Cached - Similar pages

世界文学浮士德(第-1部] - [ Translate this page

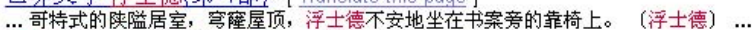
浮士德退场 (䨾非斯陀) 穿上浮士德的长袍 尽量惠视理性和学识,

166.111.4.131//wwg//ydsm2/sjwx/fsd/fsd. htm - 513k - Cached - Similar pages

Faust (JRJS) - [ Translate this page ]

Jörg RJ Schirra -- Faust-Links. ... JRJS's Faust page ..... has been moved: unw. computervisualistik. de/ schirra/Life/READ/LIB/...

simsw. cs. uni-magdeburg. de/ schirra/faust. html - $1 \mathrm{k}$ - Cached - Similar pages

外国文学- [ Translate this page ]

...浮士德》悲剧是歌德最主要的代表作, 从1770年开始构思到1831年脱稿, 前后达 . . 浮士德为欧洲中世纪传说中的一位半神话半真实的人物, 可能为魔法师, 传说他与魔鬼 ...

woxy.tsinghua. edu . cn/whfg/ydsm/66. htm - 8k - Cached - Similar pages

【表演工作坊入剧导读: 浮士德博士的悲剧 繁体]

……德 (Faust地) 叹息著生命的短暂, 他奢求具有如神一般的能力而开始研读魔法书。

…四百多年米, 有关马洛所作《浮士德博士的悲剧》一直有着版本的问题, 现今所 …

www. pwshop. com/html/article/dramaintro-0028.html - 25k - Cached - Similar pages

Figure 1. Returned mixed-language web page snippets using source query

We achieve $46 \%$ phrase translation accuracy when using 10 returned snippets, and $80 \%$ accuracy with 165 snippets. Both results are significantly better than several existing methods.

The reminder of this paper is organized as follows: cross-lingual query expansion is discussed in section 2; key phrase translation extraction is addressed in section 3 . In section 4 we present experimental results, which is followed by relevant works and conclusions.

\section{Retrieving Web Page Snippets through Cross-lingual Query Expansion}

For a Chinese key phrase $f$, we want to find its translation $e$ from the web, more specifically, from the mixed-language web pages or web page snippets containing both $f$ and $e$. As we do not know $e$, we are unable to directly retrieve such mixedlanguage web page using $(f, e)$ as the query.

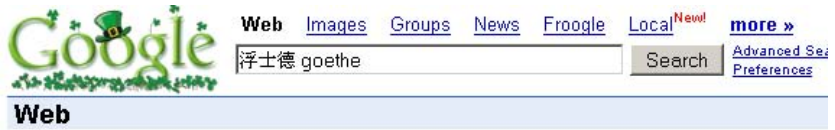

Tip: Try using pinyin for automatic Chinese keyword conversion. [Learn more about pinyin search]

Taustip: Caust (JRJS) - I Danslate this page ]

Jorg RJ Schirra -- Faust-Links. ... JRJS' Faust page mow. computervisualistik. de/ schirra/Life/READAto/

- Similar pages

诗歌 诗人 CNPoet.COM - [ Translate this page ] ... 歌德(Johann W. Goethe)诗选. 歌德 (1749-1832) , 著有诗剧《浮士德》和二千五百余首

$\ldots$ 守望者之歌一译自《浮士德》．生来为观看，矢志在守望，受命居高墽， ...

Www. cnpoet. com/waiguo/germany/001.htm - $17 \mathrm{k}$ - Cached - Similar pages

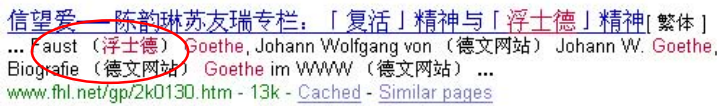

mow. fhl. net/gp/ $/ 2 \mathrm{k0130}$. htm - $13 \mathrm{k}$ - Cached - Similar pages

文学 外国文学 诗歌 歌德goethe 搜索引警 搜狐 - [ Translate this page ] …介绍歌德生平和作品《少年维持的烦恼》、《普罗米俗斯》、《衣格蒙特》、《浮士德》 等。WWw.hongen. com/edu/shfz/ywxz/sn030402.htm; 收集歌德 ...

dir. sohu com/literature/ foreign literature/poesy/goethe/ - 10k - Cached - Similar pages

歌德 (Johann W. Goethe)诗选 - [ Translate this page]

... 歌德(Johann W. Goethe)诗选. 歌德 (1749-1832) , 著有诗剧《浮士德》和二千五百 余首诗歌。浪游者之夜歌 (一) 浪游者的夜歌 (二) 《浮士德》献词重㴽对月吟 ... whw. dx.pte. sh.cn/XSLY/xingqu/shige/guowai/guowaio24.htm - 22k - Cached - Similar pages

雅虎中国网站分类> 歌德(Goethe 1749-1832) - [ Translate this page ] 雅虎网站分类歌德(Goethe 1749-1832) [登录网站] … 歌德主要作品及分析 - 介绍歌德 生平和作品《少年维特的烦恼》、《普罗米修斯》、《京格蒙特》、《浮士德》等。 ...

$\mathrm{cn}$.dir.yahoo.com/.../Germany/Arts_and_Humanities/Humanities/Literature/Authors/Johann_Wolfg.

矮脚鸡古典才说目录 Bantam Classics

... aust, 浮士德 Goethe, Johann W. 20.00. Four Comedies, 四大喜剧, Shakespeare,

Williann, 3000. Four Great American Classics, 四大美国古典名著, Melville, ...

www. bpiec.com.cn/bpiec_v2/web_dyf/_private/BantamClassics.htm - 227k - Cached - Similar page

【表演工作坊】戏剧导读: 浮士德博士的悲剧[ 繁体 ]

.... 有关浮士德的作品除子马洛的剧本外, 最出名的就是诗人歌德 (Johann Wolfgang von

Goethe) 的诗剧 《琈士德 (Faust)》 下二册, 德国剧作家革侯. …

www . pwshop. com/kim//article/dramaint $10-0028 . \mathrm{html}$ - 25k - Cached - Similar pages

Figure 2. Returned mixed-language web page snippets using cross-lingual query expansion

However, we observed that when the author of a web page lists both $f$ and $e$ in a page, it is very likely that $f^{\prime}$ and $e^{\prime}$ are listed in the same page, where $f$ ' is a Chinese hint word topically relevant to $f$, and $e^{\prime}$ is f's translation. Therefore if we know a Chinese hint word $f$ ', and we know its reliable translation, $e$ ', we can send $(f, e$ ') as a query to retrieve mixed language web pages containing $(f, e)$.

For example, to find web pages which contain translations of “浮士德”(Faust), we expand the query to “浮士德+goethe” since “歌德” (Goethe) is the author of “浮士德” (Faust). Figure 2 illustrates retrieved web page snippets with expanded queries. We find that newly returned snippets contain more correct translations with higher ranks.

To propose a "good" English hint $e^{\prime}$ for $f$, first we need to find a Chinese hint word $f^{\prime}$ that is relevant to $f$. Because $f$ is often an OOV word, it is unlikely that such information can be obtained from existing Chinese monolingual corpora. Instead, we 
query Google for web pages containing $f$. From the returned snippets we select Chinese words $f^{\prime}$ based on the following criteria:

1. $f^{\prime}$ should be relevant to $f$ based on the cooccurrence frequency. On average, 300 Chinese words are returned for each query $f$. We only consider those words that occur at least twice to be relevant.

2. $f^{\prime}$ can be reliably translated given the current bilingual resources (e.g. the LDC Chinese-English lexicon ${ }^{3}$ with 81,945 translation entries).

3. The meaning of $f^{\prime}$ should not be too ambiguous. Words with many translations are not used.

4. $f^{\prime}$ should be translated into noun or noun phrases. Given the fact that most OOV words are noun or noun phrases, we ignore those source words which are translated into other part-of-speech words. The British National Corpus ${ }^{4}$ is used to generate the English noun lists.

For each $f$, the top Chinese words $f^{\prime}$ with the highest frequency are selected. Their corresponding translations are then used as the cross-lingual hint words for $f$. For example, for OOV word $f=$ 浮士德 (Faust), the top candidate $f$ 's are “歌德 (Goethe)”, “简介 (introduction)”, “文学 (literature)” and “悲剧 (tragedy)”. We expand the original query “浮士德” to “浮士德 + goethe”, “浮士德 + introduction”, “浮士德 + literature”, “浮士德 + tragic”, and then query Google again for web page snippets containing the correct translation "Faust".

\section{Extracting Key Phrase Translation}

When the Chinese key phrase and its English hint words are sent to Google as the query, returned web page snippets contain the source query and possibly its translation. We preprocess the snippets to remove irrelevant information. The preprocessing steps are:

\section{Filter out HTML tags;}

\footnotetext{
${ }^{3}$ http://www.ldc.upenn.edu/Catalog/CatalogEntry.jsp?catalogI $\mathrm{d}=$ LDC2002L27

${ }^{4}$ http://www.natcorp.ox.ac.uk/
}

2. Convert HTML special characters (e.g., “\&lt") to corresponding ASCII code (“>”);

3. Segment Chinese words based on a maximum string matching algorithm, which is used to calculate the translation probability between a Chinese key phrase and an English translation candidate.

4. Replace punctuation marks with phrase separator '|';

5. Replace non-query Chinese words with placeholder mark ' + ', as they indicate the distance between an English phrase and the Chinese key phrase.

For example, the snippet

$$
《<\mathrm{b}>\text { 廊桥遗梦 }</ \mathrm{b}>\text { 》 (the bridges of }
$$
madison county)[review]. 发布者: anjing | 发布时间: 2004-01-25 星期日 02:13 | 最 新更新时间

is converted into

$$
\begin{aligned}
& \mid<\mathrm{b}>\text { 廊桥遗梦 }<\text { /b }>\text { | } \\
& \text { the_bridges_of_Madison_county } \mid \text { review } \mid \\
& +++\mid \text { anjing }|++++| 2004-01-25+++02 \\
& 13 \mid++++++,
\end{aligned}
$$

where " $<\mathrm{b}>$ " and “ $</ \mathrm{b}>$ " mark the start and end positions of the Chinese key phrase. The candidate English phrases, "the bridges of madison county", "review" and "anjing", will be aligned to the source key phrase according to a combined feature set using a transliteration model which captures the pronunciation similarity, a translation model which captures the semantic similarity and a frequencydistance model reflecting their relevancy. These models are described below.

\subsection{Transliteration Model}

The transliteration model captures the phonetic similarity between a Chinese phrase and an English translation candidate via string alignment. Many key phrases are person and location names, which are phonetically translated and whose written forms resemble their pronunciations. Therefore it is possible to discover these translation pairs through their surface strings. Surface string transliteration does not need a pronunciation lexicon to map words into phoneme sequences; thus it is especially appealing for OOV word translation. For non-Latin languages like Chinese, a romanization 
script called "pinyin" maps each Chinese character into Latin letter strings. This normalization makes the string alignment possible.

We adopt the transliteration model proposed in (Huang, et al. 2003). This model calculates the probabilistic Levinstein distance between a romanized source string and a target string. Unlike the traditional Levinstein distance calculation, the character alignment cost is not binary $(0 / 1)$; rather it is the logarithm of character alignment probability, which ensures that characters with similar pronunciations (e.g. 'p' and 'b') have higher alignment probabilities and lower cost. These probabilities are automatically learned from bilingual name lists using EM.

Assume the Chinese phrase $f$ has $J$ Chinese characters, $f_{1}, f_{2}, \ldots f_{J}$, and the English candidate phrase $e$ has $L$ English words, $e_{1}, e_{2}, \ldots, e_{L}$. The transliteration cost between a Chinese query $f$ and an English translation candidate $e$ is calculated as: $C_{t r l}(e, f) \approx \sum_{j} \log p\left(e_{a_{j}} \mid y_{j}\right)=\sum_{j} \sum_{i} \log p\left(e_{a_{(i, j)}} \mid y_{i, j}\right)$. where $y_{j}$ is the pinyin of Chinese character $f_{j}$, $y_{j, i}$ is the $i$ th letter in $y_{j}$, and $e_{a_{j}}$ and $e_{a_{(j, i)}}$ are their aligned English letters, respectively. $p\left(e_{(i, j)} \mid y_{i, j}\right)$ is the letter transliteration probability. The transliteration costs between a Chinese phrase and an English phrase is approximated by the sum of their letter transliteration cost along the optimal alignment path, which is identified based on dynamic programming.

\subsection{Translation Model}

The translation model measures the semantic equivalence between a Chinese phrase and an English candidate. One widely used model is the IBM model (Brown et al. 1993). The phrase translation probability is computed using the IBM model- 1 as:

$$
P_{\text {trans }}(f \mid e)=\frac{1}{L^{J}} \prod_{j=1}^{J} \sum_{l=1}^{L} p\left(f_{j} \mid e_{l}\right)
$$

where $p\left(f_{j} \mid e_{l}\right)$ is the lexical translation probabilities, which can be calculated according to the IBM models. This alignment model is asymmetric, as one source word can only be aligned to one target word, while one target word can be aligned to multiple source words. We estimate both $P_{\text {trans }}(f \mid e)$ and $P_{\text {trans }}(e \mid f)$, and define the NE translation cost as:

$$
C_{\text {trans }}(e, f)=\log P_{\text {trans }}(e \mid f)+\log P_{\text {trans }}(f \mid e) .
$$

\subsection{Frequency-Distance Model}

The more often a bilingual phrase pair co-occurs, or the closer a bilingual phrase pair is within a snippet, the more likely they are translations of each other. The frequency-distance model measures this correlation.

Suppose $S$ is the set of returned snippets for query $f$, and a single returned snippet is $s_{i} \in S$. The source phrase occurs in $s_{i}$ as $f_{i, j}(j \geq 1$ since $f$ may occur several times in a snippet). The frequency-distance weight of an English candidate $e$ is

$$
w(e)=\sum_{s_{i}} \sum_{f_{i, j}} \frac{1}{d\left(f_{i, j}, e\right)}
$$

where $d(f, e)$ is the distance between phrase $f_{i, j}$ and $e$, i.e., how many words are there between the two phrases (the separator $`$ is not counted).

\subsection{Feature Combination}

Define the confidence measure for the transliteration model as:

$$
\phi_{t r l}(e \mid f)=\frac{\exp \left[C_{t r l}(e, f)\right] w(e)^{m}}{\sum_{e^{\prime}} \exp \left[C_{t r l}\left(e^{\prime}, f\right)\right] w\left(e^{\prime}\right)^{m}},
$$

where $e$ and $e$ ' are English candidate phrases, and $m$ is the weight of the distance model. We empirically choose $\mathrm{m}=2$ in our experiments. This measure indicates how good the English phrase $e$ is compared with other candidates based on transliteration model. Similarly the translation model confidence measure is defined as:

$$
\phi_{\text {trans }}(e \mid f)=\frac{\exp \left[C_{\text {trans }}(e, f)\right] w(e)^{m}}{\sum_{e^{\prime}} \exp \left[C_{\text {trans }}\left(e^{\prime}, f\right)\right] w\left(e^{\prime}\right)^{m}} .
$$

The overall feature cost is the linear combination of transliteration cost and translation cost, which are weighted by their confidence scores respectively: 


$$
\begin{aligned}
& C(e, f)=\lambda \phi_{t r l}(e \mid f) \exp \left[C_{t r l}(e, f)\right]+ \\
& (1-\lambda) \phi_{\text {trans }}(e \mid f) \exp \left[C_{\text {trans }}(e, f)\right]
\end{aligned}
$$

where the linear combination weight $\lambda$ is chosen empirically. While $\phi_{\text {trl }}$ and $\phi_{\text {trans }}$ represent the relative rank of the current candidate among all compared candidates, $C_{\text {trl }}$ and $C_{\text {trans }}$ indicate its absolute likelihood, which is useful to reject the top 1 incorrect candidate if the true translation does not occur in any returned snippets.

\section{Experiments}

We evaluated our approach by translating a set of key phrases from different domains. We selected 310 Chinese key phrases from 12 domains as the test set, which were almost equally distributed within these domains. We also manually translated them as the reference translations. Table 1 shows some typical phrases and their translations, where one may find that correct key phrase translations need both phonetic transliterations and semantic translations. We evaluated inclusion rate, defined as the percentage of correct key phrase translations which can be retrieved in the returned snippets; alignment accuracy, defined as the percentage of key phrase translations which can be correctly aligned given that these translations are included in the snippets; and overall translation accuracy, defined as the percentage of key phrases which can be translated correctly. We compared our approach with the LiveTrans ${ }^{5}$ (Cheng et.al. 2004) system, an unknown word translator using web corpora, and we observed better translation performance using our approach.

\subsection{Query Translation Inclusion Rate}

In the first round query search, for each Chinese key phrase $f$, on average 13 unique snippets were returned to identify relevant Chinese hint words $f$, and the top $5 f$ 's were selected to generate hint words $e$ 's. In the second round $f$ and $e$ 's were sent to Google again to retrieve mixed language snippets, which were used to extract $e$, the correct translation of $f$.

Figure 3 shows the inclusion rate vs. the number of snippets used for three mixed-language web page searching strategies:

\begin{tabular}{|c|c|}
\hline Movie Title & $\begin{array}{l}\text { 廊桥遗梦 the Bridges of Madison- } \\
\text { County } \\
\text { 阿甘正传 } \quad \text { Forrest Gump }\end{array}$ \\
\hline Book Title & $\begin{array}{l}\text { 红楼梦 } \quad \text { Dream of the Red Mansion } \\
\text { 茶花女 } \quad \text { La Dame aux camellias }\end{array}$ \\
\hline $\begin{array}{r}\text { Organization } \\
\text { Name }\end{array}$ & $\begin{array}{l}\text { 圣母大学 University of Notre Dame } \\
\text { 大卫与露西派克德基金会 David and } \\
\text { Lucile Packard Foundation }\end{array}$ \\
\hline $\begin{array}{r}\text { Person } \\
\text { Name }\end{array}$ & $\begin{array}{lc}\text { 贝多芬 } & \text { Ludwig Van Beethoven } \\
\text { 奥黛丽赫本 } & \text { Audrey Hepburn }\end{array}$ \\
\hline $\begin{array}{r}\text { Location } \\
\text { Name }\end{array}$ & $\begin{array}{l}\text { 勘察加半岛 } \quad \text { Kamchatka } \\
\text { 塔克拉玛干沙漠Taklamakan desert }\end{array}$ \\
\hline $\begin{array}{r}\text { Company / } \\
\text { Brand }\end{array}$ & $\begin{array}{ll}\text { 汉莎航空 } & \text { Lufthansa German } \\
\text { Airlines } & \\
\text { 雅诗兰黛 } & \text { Estee Lauder } \\
\end{array}$ \\
\hline $\begin{array}{r}\text { Sci\&Tech } \\
\text { Terms }\end{array}$ & $\begin{array}{l}\text { genetic algorithm } \\
\text { speech recognition }\end{array}$ \\
\hline Specie Term & $\begin{array}{l}\text { Aegypius monachus } \\
\text { Manispentadactyla }\end{array}$ \\
\hline $\begin{array}{r}\text { Military } \\
\text { Term } \\
\end{array}$ & $\begin{array}{ll}\text { 宙斯盾 } & \text { Aegis } \\
\text { 费尔康 } & \text { Phalcon } \\
\end{array}$ \\
\hline $\begin{array}{r}\text { Medical } \\
\text { Term }\end{array}$ & $\begin{array}{ll}\text { 非典型性肺炎 } & \text { SARS } \\
\text { 动脉硬化 } & \text { Arteriosclerosis }\end{array}$ \\
\hline Music Term & $\begin{array}{ll}\text { 空山鸟语 } & \text { Bird-call in the Mountain } \\
\text { 巴松管 } & \text { Bassoon }\end{array}$ \\
\hline Sports Term & $\begin{array}{ll}\text { 休斯敦火箭队 } & \text { Houston Rockets } \\
\text { 环法自行车赛 } & \text { Tour de France }\end{array}$ \\
\hline
\end{tabular}

\footnotetext{
${ }^{5}$ http://livetrans.iis.sinica.edu.tw/lt.html
}

Table 1. Test set key phrases

- $\quad$ Search any web pages containing $f$ (Zhang and Vines 2004);

- Only search English web pages ${ }^{6}$ containing $f$ (Cheng et al. 2004);

- Search any web pages containing $f$ and hint words $e^{\prime}$, as proposed in this paper.

The first search strategy resulted in a relatively low inclusion rate; the second achieved a much higher inclusion rate. However, because such English pages were limited, and on average only 45 unique snippets could be found for each $f$, which resulted in a maximum inclusion rate of $85.8 \%$. In the case of the cross-lingual query expansion, the search space was much larger but more focused and we achieved a high inclusion rate of $89.7 \%$ using 32 mixed-language snippets and $95.2 \%$ using 165 snippets, both from the second round retrieval.

\footnotetext{
${ }^{6}$ These web pages are labeled by Google as “English” web pages, though they may contain non-English characters.
} 


\begin{tabular}{|c|c|c|}
\hline Features & $\begin{array}{c}\text { No Hints } \\
\text { (Inc = 44.19\%) } \\
\text { (avg. snippets }= \\
\text { 10) }\end{array}$ & $\begin{array}{c}\text { With Hints } \\
\text { (Inc = 95.16\%) } \\
\text { (avg. snip- } \\
\text { pets=130) }\end{array}$ \\
\hline Trl & 51.45 & 17.97 \\
\hline Trans & 51.45 & 40.68 \\
\hline Fq-dis & 53.62 & 73.22 \\
\hline Trl+Trans & 63.04 & 51.36 \\
\hline $\begin{array}{c}\text { Trl+Trans+ } \\
\text { Fq-dis }\end{array}$ & 65.94 & 86.73 \\
\hline
\end{tabular}

Table 2. Alignment accuracies using different features

These search strategies are further discussed in the section 5 .

\subsection{Translation Alignment Accuracy}

We evaluated our key phrase extraction model by testing queries whose correct translations were included in the returned snippets. We used different feature combinations on differently sized snippets to compare their alignment accuracies. Table 2 shows the result. Here "Trl" means using the transliteration model, "Trans" means using the translation model, and "Fq-dis" means using FrequencyDistance model. The frequency-distance model seemed to be the strongest single model in both cases (with and without hint words), while incorporating phonetic and semantic features provided additional strength to the overall performance. Combining all three features together yielded the best accuracy. Note that when more candidate translations were available through query expansion, the alignment accuracy improved by $30 \%$ relative due to the frequency-distance model. However, using transliteration and/or translation models alone decreased performance because of more incorrect translation candidates from returned snippets. After incorporating the frequencydistance model, correct translations have the maximum frequency-distance weights and are more likely to be selected as the top hypothesis. Therefore the combined model obtained the highest translation accuracy.

\subsection{Overall Translation Quality}

The overall translation qualities are listed in Table 3 , where we showed the translation accuracies of

\begin{tabular}{|c|c|c|c|c|c|}
\hline Snippets & \multicolumn{4}{|c}{ Accuracy of the Top-N Hyp. (\%) } \\
\cline { 2 - 6 } Used & Top1 & Top2 & Top3 & Top4 & Top5 \\
\hline $\mathbf{1 0}$ & 46.1 & 55.2 & 59.0 & 61.3 & 62.3 \\
\hline $\mathbf{2 0}$ & 57.4 & 64.2 & 69.7 & 72.6 & 72.9 \\
\hline $\mathbf{5 0}$ & 63.2 & 74.5 & 77.7 & 79.7 & 80.6 \\
\hline $\mathbf{1 0 0}$ & 75.2 & 84.5 & 85.8 & 87.4 & 87.4 \\
\hline $\mathbf{1 6 5}$ & $\mathbf{8 0 . 0}$ & $\mathbf{8 6 . 5}$ & $\mathbf{8 9 . 0}$ & $\mathbf{9 0 . 0}$ & $\mathbf{9 0 . 0}$ \\
\hline \hline $\begin{array}{r}\text { Babel- } \\
\text { Fish } \mathbf{\text { MT }}\end{array}$ & 31.3 & N/A & N/A & N/A & N/A \\
\hline $\begin{array}{r}\text { CMU- } \\
\text { SMT }\end{array}$ & 21.9 & N/A & N/A & N/A & N/A \\
\hline $\begin{array}{r}\text { LiveTrans } \\
\text { (Fast) }\end{array}$ & 20.6 & 30.0 & 36.8 & 41.9 & 45.2 \\
\hline $\begin{array}{r}\text { LiveTrans } \\
\text { (Smart) }\end{array}$ & 30.0 & 41.9 & 48.7 & 51.0 & 52.9 \\
\hline
\end{tabular}

Table 3. Overall translation accuracy

the top 5 hypotheses using different number of snippets. A hypothesized translation was considered to be correct when it matched one of the reference translations. Using more snippets always increased the overall translation accuracy, and with all the 165 snippets (on average per query), our approach achieved 80\% top-1 translation accuracy, and $90 \%$ top-5 accuracy.

We compared the translations from a research statistical machine translation system (CMU-SMT, Vogel et al. 2003) and a web-based MT engine (BabelFish). Due to the lack of topic-relevant contexts and many OOV words occurring in the source key phrases, their results were not satisfactory. We also compare our system with LiveTrans, which only searched within English web pages, thus with limited search space and more noises (incorrect English candidates). Therefore it was more difficult to select the correct translation. Table 4 lists some example key phrase translations mined from web corpora, as well as translations from the $\mathrm{Ba}-$ belFish.

\section{Relevant Work}

Both (Cheng et al. 2004) and (Zhang and Vines 2004) exploited web corpora for translating OOV terms and queries. Compared with their work, our proposed method differs in both webpage search

\footnotetext{
${ }^{7}$ http://babelfish.altavista.com/
} 


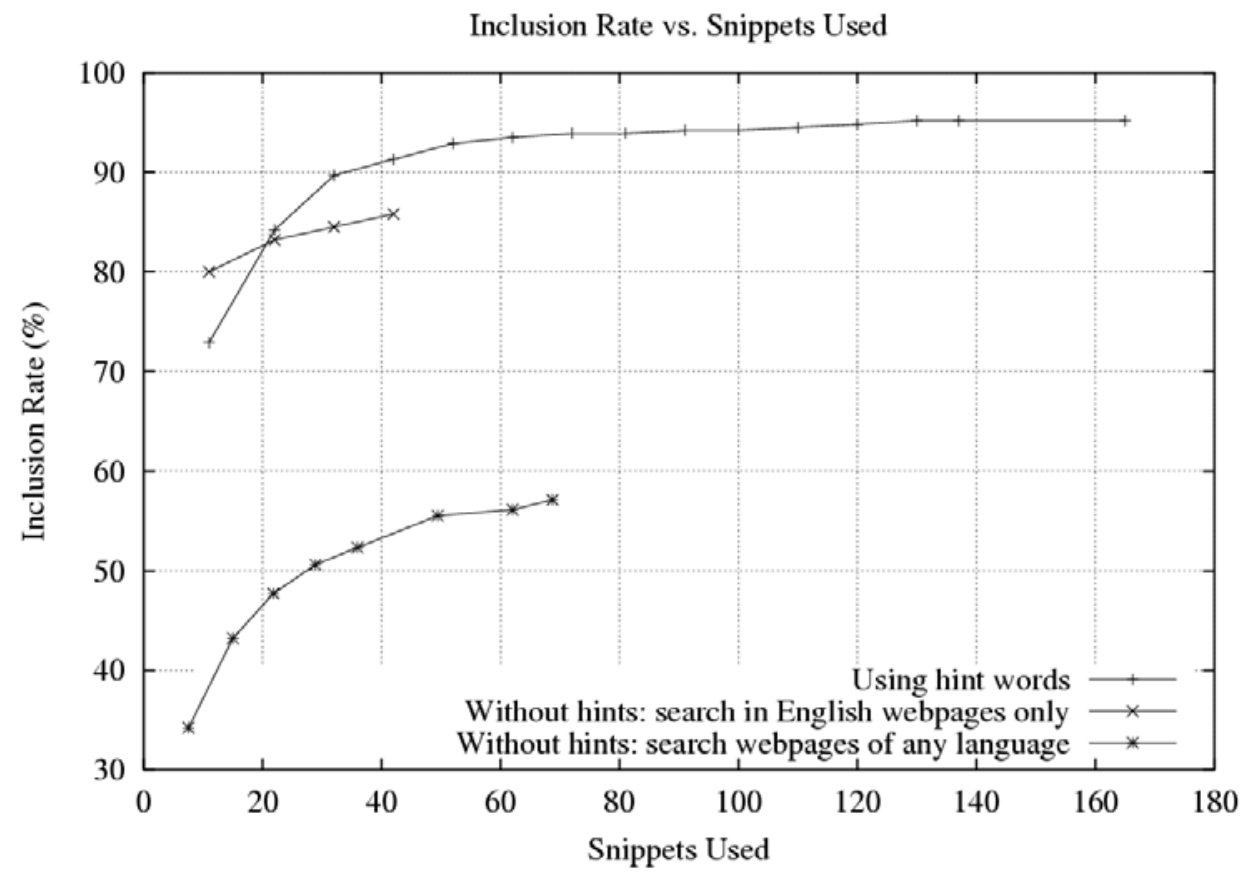

Figure 3. Inclusion rate vs. the number of snippets used

\begin{tabular}{|c|c|c|c|}
\hline \multirow{2}{*}{ Category } & \multicolumn{3}{|c|}{ Examples } \\
\hline & Chinese Key Phrase & Web-Mining Translation & BabelFish ${ }^{\mathrm{TM}}$ Result \\
\hline $\begin{array}{r}\text { Movie } \\
\text { Title } \\
\end{array}$ & 廊桥遗梦 & $\begin{array}{l}\text { the Bridges of Madison } \\
\text { County }\end{array}$ & $\begin{array}{l}\text { *Love has gone and only good } \\
\text { memory has left in the dream }\end{array}$ \\
\hline $\begin{array}{r}\text { Book } \\
\text { Title } \\
\end{array}$ & 理智与情感 & Sense and Sensibility & *Reason and emotion \\
\hline $\begin{array}{r}\text { Organization } \\
\text { Name } \\
\end{array}$ & $\begin{array}{c}\text { 伍德威尔逊全国联谊基 } \\
\text { 金会 } \\
\end{array}$ & $\begin{array}{l}\text { Woodrow Wilson National } \\
\text { Fellowship Foundation }\end{array}$ & $\begin{array}{l}\text { *Wood the Wilson nation gets to- } \\
\text { gether the foundation }\end{array}$ \\
\hline \begin{tabular}{r|} 
Person \\
Name \\
\end{tabular} & 小泽征尔 & Seiji Ozawa & *Young Ze drafts you \\
\hline $\begin{array}{r}\text { Location } \\
\text { Name } \\
\end{array}$ & 柴达木盆地 & Tsaidam Basin & Qaidam Basin \\
\hline $\begin{array}{r}\text { Company / } \\
\text { Brand }\end{array}$ & 倩碧 & Clinique & *Attractive blue \\
\hline $\begin{array}{r}\text { Sci\&Tech } \\
\text { Terms } \\
\end{array}$ & 贝叶斯网络 & Bayesian network & *Shell Ye Si network \\
\hline $\begin{array}{r}\text { Specie } \\
\text { Term }\end{array}$ & 海象 & walrus & walrus \\
\hline $\begin{array}{r}\text { Military } \\
\text { Term }\end{array}$ & 同温层堡垒 & stratofortress & stratofortress \\
\hline $\begin{array}{r}\text { Medical } \\
\text { Term } \\
\end{array}$ & 青光眼 & glaucoma & glaucoma \\
\hline $\begin{array}{r}\text { Music } \\
\text { Term } \\
\end{array}$ & 巴松管 & bassoon & bassoon \\
\hline $\begin{array}{r}\text { Sports } \\
\text { Term }\end{array}$ & 环法自行车赛 & Km Tour de France & ${ }^{*}$ Link law bicycle match \\
\hline
\end{tabular}

*: Incorrect translations

Table 4. Key phrase translation from web mining and a MT engine 
space and translation extraction features. Figure 4 illustrates three different search strategies. Suppose we want to translate the Chinese query “浮士德”. (Cheng et al. 2004) only searched 188 English web pages which contained the source query, and 53\% of them (100 pages) had the correct translations. (Zhang and Vines 2004) searched the whole 55,100 web pages, $10 \%$ of them (5490 pages) had the correct translation. Our approach used query expansion to search any web pages containing “浮 士德” and English hint words, which was a larger search space than (Cheng et al. 2004) and more focused compared with (Zhang and Vines 2004), as illustrated with the shaded region in Figure 4. For translation extraction features, we took advantage of machine transliteration and machine translation models, and combined them with frequency and distance information.

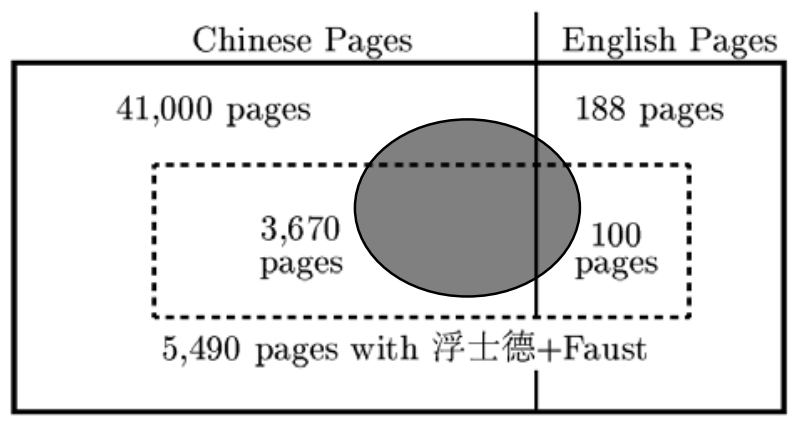

55,100 pages with 浮士德

Figure 4. Web search space strategy comparison

\section{Discussion and Future Work}

In this paper we demonstrated the feasibility of the proposed approach by searching for the English translation for a given Chinese key phrase, where we use punctuations and Chinese words as the boundary of candidate English translations. In the future we plan to try more flexible translation candidate selection methods, and apply them to other language pairs. We also would like to test our approach on more standard test sets, and compare the performance with other systems.

Our approach works on short snippets for query expansion and translation extraction, and the computation time is short. Therefore the search engine's response time is the major factor of computational efficiency.

\section{Conclusion}

We proposed a novel approach to mine key phrase translations from web corpora. We used crosslingual query expansion to retrieve more relevant web pages snippets, and extracted target translations combining transliteration, translation and frequency-distance models. We achieved significantly better results compared to the existing methods.

\section{References}

P. F. Brown, S. A. Della Pietra, V. J. Della Pietra and R.L. Mercer. The Mathematics of Machine Translation: Parameter Estimation. In Computational Linguistics, vol 19, number 2. pp.263-311, June, 1993.

P.-J. Cheng, J.-W. Teng, R.-C. Chen, J.-H. Wang, W.-H. $\mathrm{Lu}$, and L.-F. Chien. Translating unknown queries with web corpora for cross-language information retrieval. In the Proceedings of 27th ACM SIGIR, pp146-153. ACM Press, 2004.

F. Huang, S.Vogel and A. Waibel. Automatic extraction of named entity translingual equivalence based on multi-feature cost minimization. In the Proceedings of the 41st ACL. Workshop on Multilingual and Mixedlanguage Named Entity Recognition, pp124-129, Sapporo, Japan, July 2003.

W.-H. Lu, L.-F. Chien, H.-J. Lee. Translation of web queries using anchor text mining. ACM Trans. Asian Language Information Processing (TALIP) 1(2): 159172 (2002)

P. Resnik and N. A. Smith, The Web as a Parallel Corpus, Computational Linguistics 29(3), pp. 349-380, September 2003

S. Vogel, Y. Zhang, F. Huang, A. Tribble, A. Venogupal, B. Zhao and A. Waibel. The CMU statistical machine translation system. In Proceedings of the MT Summit IX Conference New Orlean, LA, September, 2003.

Y. Zhang and P. Vines. Detection and Translation of OOV Terms Prior to Query Time, In the Proceedings of 27th ACM SIGIR. pp524-525, Sheffield, England, 2004.

Y. Zhang and P. Vines 2004, Using the Web for Automated Translation Extraction in Cross-Language Information Retrieval, In Proceedings of 27th ACM SIGIR, pp.162-169, Sheffield, United Kingdom, 2004.

Y. Zhang, F. Huang and S. Vogel, Mining Translations of OOV Terms from the Web through Cross-lingual Query Expansion, in the Proceedings of the 28th ACM SIGIR, Salvador, Brazil, August 2005. 